\title{
Nilai Pendidikan Karakter pada Cerpen Waskat Karya Wisran Hadi
}

\author{
Suhardi ${ }^{1}$, Afifah Thahirah ${ }^{2}$ \\ ${ }^{1}$ Universitas Maritim Raja Ali Haji Tanjungpinang \\ ${ }^{2}$ Pascasarjana UIN Suska Riau \\ afifahthahirahh@gmail.com; suhardi.tp@gmail.com
}

\begin{abstract}
How to cite (in APA Style): Suhardi, \& Thahirah, A. (2018). Nilai pendidikan karakter pada cerpen Waskatkarya Wisran Hadi. Jurnal Pendidikan Babasa dan Sastra, 18(1), 114-122, doi: 10.17509/bs_jpbsp.v18i1.12151
\end{abstract}

Article History: Received (February 24, 2018); Revised (March 18, 2018); Accepted (March 29, 2018).

Journal homepage: http://ejournal.upi.edu./index.php/BS_JPBSP

\begin{abstract}
Abstrak: Penelitian ini bertujuan untuk mendeskripsikan nilai pendidikan karakter dalam cerpen Waskat karya Wisran Hadi. Penelitian ini menggunakan metode deskriptif. Sumber data adalah cerpen Waskat karya Wisran Hadi. Pengumpulan data dilakukan dengan cara membaca dan memahami cerpen dengan cermat serta melakukan pencatatan terhadapat nilai-nilai pendidikan karakter yang terkandung di dalam cerpen. Analisis data dilakukan dengan mengikuti model Miles dan Huberman (1992), yaitu: (1) melakukan identifikasi cerpen Waskat sebagai objek penelitian, (2) melakukan reduksi data, (3) menyajikan data, (4) menginterpretasikan data yang diperoleh sesuai teori, dan (5) menyusun simpulan. Hasil penelitian menunjukkan bahwa cerpen Waskat karya Wisran Hadi mengandung nilai-nilai pendidikan karakter, seperti nilai: (1) relegius, (2) kejujuran, (3) toleransi, (4) disiplin, (5) kerja keras, (6) mandiri, (7) komunikatif, (8) cinta damai, dan nilai (9) peduli sosial.Kesembilan nilai tersebut menyatu keberadaannya dalam cerpen. Selain itu, karena cerpen Waskat ini juga diselingi humor-humor kecil maka cerpen ini juga dapat menjadi hiburan bagi pembaca.
\end{abstract}

Kata kunci: nilai, pendidikan karakter, cerpen

\section{The Values of Educational Character in Waskat Short Story by Wisran Hadi}

\begin{abstract}
This research aims to describe the values of educational character in Waskat short story by Wisran Hadi. This research used descriptive method. The source of the data is the short story "Waskat" written by Wisran Hadi. The data were collected through reading and understanding of the short story carefully and recording educational character values found in the short story. Data analyses were done using Miles and Huberman's model (1992), namely: (1) identifying the short story Waskat as the object of the research, (2) reducing the data, (3) presenting the data, (4) interpreting the data obtained by theory, and (5) making conclusion. The results show that Waskat short story contains character education values, such as: (1) religiosity, (2) honesty, (3) tolerance, (4) discipline, (5) rigor, (6) independence, (7) communicativeness, (8) love of peace, and the value of (9) social care. In addition, this short story also contains sense of humor which entertains the reader.
\end{abstract}

Keyword: values, educational character, short story 


\section{PENDAHULUAN}

Arus globalisasi yang melanda dunia saat ini, tak terkecuali Indonesia, tidak hanya membawa efek positif terhadap pola tingkah laku masyarakat, juga membawa efek negatif. Bahkan bila tidak cepat dilakukan antisipasi ke depan dapat menimbulkan efek yang sangat buruk, khususnya terhadap perilaku masyarakat. Lihat apa yang terjadi di lingkungan tempat kita tinggal, lalu bandingkan dengan situasi yang terjadi pada masa kecil kita dulu (tradisi). Sudah banyak hal-hal yang aneh terjadi saat ini yang menyimpang dari tradisi yang kita junjung selama ini.

Dalam hal tradisi tegur sapa, misalnya. Menurut tradisi yang dianut selama ini, seseorang dianjurkan jika berpapasan dengan orang tua atau yang lebih tua mengucapkan salam. Namun saat ini, tradisi tersebut sudah mulai ditinggalkan (hilang) dalam kehidupan sehari-hari. Begitu juga dalam hal berpakaian seringkali tidak sesuai dengan norma masyarakat yang telah ada. Oleh karena itu, apa yang terjadi saat ini sangatlah jauh berbeda keadaannya bahkan bertolak belakang dengan tradisi yang dianut selama ini oleh masyarakat.

Begitu juga dalam hal kewajiban mengabdi kepada orang tua. Kita telah banyak melihat para orangtua yang dimasukkan oleh anak-anaknya ke panti jompo setelah dirinya tua. Pada hal anakanak mereka hidup mapan. Padahal dalam agama mereka tidak ditemukan satu ayat pun yang menyatakan bahwa mereka memiliki kewajiban memasukkan orangtuanya kelak setelah tua ke panti jompo. Inilah realitas yang terlihat di masa kini banyak sekali hal yang menyimpang dari tata kehidupan masyarakat yang selama ini dijunjung tinggi.

Masyarakat Indonesia saat ini banyak ahli yang menyatakan sedang dilanda krisis identitas, krisis tradisi asli nenek moyangnya, atau krisis moral. Hal tersebut sebagaimana diungkapkan oleh Syarbaini (2014,p.1) bahwa perubahan yang terjadi begitu cepat membawa efek terhadap tatanan kehidupan manusia. Nilai-nilai yang mejadi panutan hidup selama ini kini telah kehilangan otoritasnya, sehingga menimbulkan berbagai krisis, khususnya krisis moral dan perilaku. Pemerintah harus melakukan antisipasi khususnya dalam bidang pendidikan.

Kemendiknas melalui Badan

Penelitian dan Pengembangan Pusat Kurikulum dan Perbukuan 2011, telah menyusun buku panduan tentang pendidikan karakter. Terdapat 18 nilai pendidikan karakter yang harus diwujudkan dalam setiap pembelajaran di sekolah. Kedelapan belas nilai tersebut bersumber dari agama, Pancasila, budaya, dan tujuan pendidikan nasional. Kedelapan belas nilai-nilai pendidikan karakter tersebut meliputi: nilai (1) religius, (2) jujur, (3) toleransi, (4) disiplin, (5) kerja keras, (6) kreatif, (7) mandiri, (8) demokratis, (9) rasa ingin tahu, (10) semangat kebangsaan, (11) cinta tanah air, (12) menghargai pres-tasi, (13) bersahabat/komunikatif, (14) cinta damai, (15) gemar membaca, (16) peduli lingkungan, (17) peduli sosial, (18) tanggung jawab (Pusat Kurikulum, 2009, p.9-10).

Krisis moral dan perilaku yang terjadi di kalangan generasi muda saat ini sebetulnya dapat diatasi dengan menghadapkan mereka pada berbagai jenis karya sastra. Karya sastra dapat dijadikan alat terapi dalam pembentukan moral yang baik. Sumardjo dan Saini (1986, p.8-10) menyatakan bahwa membaca karya sastra memberikan beberapa manfaat bagi pembacanya, yaitu: (1) memberikan kesa-daran tentang kebenaran hidup, (2) membe-rikan penghayatan yang mendalam tentang realitas yang ada, dan (3) menjadikan pembacanya menjadi manusia yang berbudaya. Hal yang sama juga diungkapkan oleh Nurgiyantoro (1995, p. 322) yang menyatakan bahwa karya fiksi senantiasa menawarkan pesan moral yang berhubungan dengan sifat-sifat luhur kemanusiaan, memperjuangkan hak dan martabat manusia.

Agar nilai-nilai yang terkandung dalam karya sastra dapat diungkapkan, seorang penganalisis harus menguasai ilmu tentang kode (Semiotik). Menurut Segers (2000, p.4) bahwa kajian semiotik adalah disiplin ilmu yang menyelidiki semua bentuk komunikasi 
yang terjadi melalui sistem 'tanda-tanda' dan berdasarkan 'sistem tanda' (signs system). Pandangan yang sama juga dikemukakan Teeuw (1991,p.12-13). Cuma Teeuw menyebut tanda dengan sebutan kode. Menurut Teeeuw, membaca karya sastra adalah proses memahami kode-kode yang terdapat di dalamnya. Baik kode bahasa, kode sastra, maupun kode budaya. Seorang pembaca yang baik harusnya memahami dan menguasai ketiga kode tersebut agar pemahamannya sempurna.

Menurut Fokkema dan Kunne (1998, p. 211), kajian semiotik saat ini sedang hangat dibicarakan. Realitas tersebut memper-lihatkan kajian semiotik merupakan kajian yang sangat popular saat ini. Faruk (1994, p. 17) mengutip pandangan Goldmann yang menyatakan bahwa karya sastra merupakan ekspresi pandangan dunia yang imajiner.

Dalam upaya mengekspresikan pandangan dunia itu, pengarang menciptakan semesta tokoh-tokoh, objek-objek, dan relasi secara imajiner." Mahayana (2007,p.xiv) mengutarakan bahwa melalui keberagaman suku bangsa dalam lingkungan keindonesia, sastra Indonesia memiliki peluang untuk melakukan penggalian dan pemanfaatan keberagaman tersebut sebagai pintu masuk membangun kebangsaan Indonesia dengan segala perbedaan yang dimiliki, keberagaman, dan heterogenitasnya.

Djamaris (1994,p.16) mengatakan sastra itu sendiri mengandung nilai-nilai budaya berupa nilai kehidupan, moral, hukum, dan sebagainya. Sastra nusantara dapat dijadikan sarana pemantapan nilai-nilai budaya itu. Koentjaraningrat dalam Djamaris (1994, p.17) juga menyatakan, bahwa "nilainilai budaya itu adalah tingkat pertama kebudayaan ideal atau adat; lapisan yang paling abstrak dan luas ruang lingkupnya; ide-ide yang mengkonsepsikan hal-hal yang paling bernilai dalam kehidupan masyarakat; dan konsepsi-konsepsi yang hidup dalam alam pikiran sebagian besar warga masyarakat mengenai hal-hal yang harus mereka anggap amat bernilai dalam hidupnya. Nilai budaya berfungsi sebagai pedoman tertinggi bagi prilaku manusia".

Nama Wisran Hadi sebagai sastrawan senior Indonesia tidak asing lagi bagi masyarakat Indonesia. Karya-karyanya sudah banyak beredar di masyarakat, bahkan sering menjadi objek kajian (penelitian). Hal tersebut sebagaimana dilakukan Mursal Esten yang menjadikan teks sandiwara Cindua Mato karya Wisran Hadi sebagai objek kajian disertasinya. Disertasi tersebut juga telah dibukukan Esten dengan judul "Kajian Trasformasi Budaya". Menurut Esten (1999: 220), "karya sandiwara Wisran Hadi yang berjudul Cindua Mato merupakan pemahaman baru terhadap mitos Cindua Mato".

Asri (2013) melakukan penelitian terhadap novel "Negeri Perempuan" karya Wisran Hadi sebagai objek penelitian dengan judul, "Refleksi Ideologi Wanita dalam Novel Negeri Perempuan Karya Wisran Hadi. Hasil yang diperoleh adalah ada dua bentuk ideologi yang terefleksi dalam novel ini, yakni ideologi sosial dan ideologi politik. Ideologi sosial yang menonjol adalah ideologi feodal dan neofeodal. Ideologi feodal terefleksi pada tokoh perempuan pewaris kerajaan yang selalu berpandangan masalah warisan dan tata cara pengangkatan penghulu sesuai dengan aturan adat yang berlaku, sedangkan ideologi neofeodal yang didukung oleh tokoh perempuan istri pejabat dan saudara konglomerat yang berpandangan bahwa tata cara warisan.

Rais (2017) juga melakukan penelitian terhadap naskah drama "Jalan Lurus" karya Wisran Hadi dengan judul, "Absurditas dalam Naskah Drama Jalan Lurus Karangan Wisran Hadi dan Implikasinya Dalam Pembelajaran Sastra di SMA". Hasil penelitian ini menunjukkan bahwa drama "Jalan Lurus" karangan Wisran Hadi merupakan bentuk drama absurd. Absurditas tersebut ialah makna hidup, keterasingan, bunuh diri, harapan, dan pemberontakan. Tema makna hidup paling sering disampaikan dalam naskah drama "Jalan Lurus". Sementara itu, tema bunuh diri dan pemberontakan dalam naskah drama "Jalan 
Lurus" menjadi tema yang paling sedikit disampaikan. Implikasinya dalam pembelajaran sastra di SMA, guru dapat menggunakan drama ini sebagai alternatif bahan ajar. Namun, hal tersebut perlu disesuaikan dengan perkembangan siswa.

Mengacu pada permasalahan di atas, penelitian ini berupaya untuk mendeskripsikan nilai pendidikan karakter dalam cerpen Waskat karya Wisran Hadi

\section{METODE}

Penelitian ini menggunakan metode deskriptif, hermeneutika, atau metode analisis isi, yaitu suatu metode dengan cara kerja memberikan interpretasi, pemahaman terhadap objek yang diamati (Ratna, 2011, p.44). Ghony dan Almanshur, (2012, p.89) mengatakan bahwa metode dekriptif bertujuan untuk mendeskripsikan dan menganalisis fenomena, peristiwa, aktivitas sosial, sikap, kepercayaan, persepsi, dan pemikiran orang secara individu maupun secara kelompok.

Metode deskriptif digunakan dalam kajian ini dengan maksud untuk mendeskripsikan manifestasi 18 nilai-nilai pendidikan karakter yang terkandung dalam cerpen Waskat karya Wisran Hadi. Nilai-nilai tersebut meliputi nilai: (1) religius, (2) jujur, (3) toleransi, (4) disiplin, (5) kerja keras, (6) kreatif, (7) mandiri, (8) demok-ratis, (9) rasa ingin tahu, (10) semangat kebangsaan, (11) cinta tanah air, (12) menghargai prestasi, (13) bersa-habat / komunikatif, (14) cinta damai, (15) gemar membaca, (16) peduli lingkungan, (17) peduli sosial, dan nilai (18) tanggung jawab. Pengumpulan data dilakukan dengan cara membaca cerpen dan melakukan pencatatan terhadap isi cerpen. Analisis data dilakukan dengan mengikuti model Miles dan Huberman (1992), dengan langkah-langkah: (1) melakukan identifikasi cerpen Waskat sebagai objek penelitian, (2) melakukan reduksi data, (3) menyajikan data, (4) menginterpretasikan data yang diperoleh sesuai teori, dan (5) menyusun simpulan.

\section{HASIL DAN PEMBAHASAN}

Hasil penelitian yang diperoleh menunjukkan bahwa cerpen Waskat karya Wisran Hadi mengandung nilai-nilai pendidikan karakter, seperti nilai: (1) religius, (2) kejujuran, (3) toleransi, (4) disiplin, (5) kerja keras, (6) mandiri, (7) komunikatif, (8) cinta damai, dan nilai (9) peduli sosial. Distribusi nilai-nilai tersebut dapat dilihat pada tabel 01. Nilai-nilai tersebut di dalam cerpen berpadu dan membangun cerpen secara utuh.

Setelah dilakukan proses membaca, analisis dan pemahaman cerpen maka diperoleh data bahwa cerpen "Waskat" karya Wisran Hadi, mengandung nilai-nilai pendidikan karakter. Adapun nilai-nilai pendidikan karakter tersebut sebagaimana terlihat melalui Tabel 01 berikut ini:

Tabel 01: Nilai pendidikan karakter

\begin{tabular}{clcc}
\hline No. & \multicolumn{1}{c}{ NPK } & Koreksi & Ket. \\
\hline 1 & religius & $\sqrt{ }$ & ada \\
2 & kejujuran & $\sqrt{ }$ & ada \\
3 & toleransi & $\sqrt{ }$ & ada \\
4 & disiplin & $\sqrt{ }$ & ada \\
5 & kerja keras & $\sqrt{ }$ & ada \\
6 & mandirit & $\sqrt{ }$ & ada \\
7 & komunikatif & $\sqrt{ }$ & ada \\
8 & Cinta damai & $\sqrt{ }$ & ada \\
9 & Peduli sosial & $\sqrt{ }$ & ada \\
\hline
\end{tabular}

\section{Nilai Religius (agama)}

Yang dimaksud dengan nilai religius di sini adalah aplikasi norma-norma agama (Islam) dalam kehidupan sehari-hari. Tokoh si Lumpuh dan si Buta tidak merasa risih sedikit pun dengan adanya tindakan pengawasan ketat terhadap berbagai pejabat instansi oleh pemerintah. Adanya pengawasan ketat yang dilakukan pemerintah tersebut tidak akan menghalangi dirinya untuk dapat mendengarkan orang lain. Begitu juga untuk berbuat baik pada orang lain. Hal ini sangat berbeda dengan tokoh (pejabat) yang merasakan bahwa pengawasan ketat yang dilakukan pemerintah sangat membuat dirinya menjadi lumpuh. 
"Yang lumpuh sering tertawa apa-bila ada seorang yang tegap dan cepat berjalannya menyatakan bahwa dirinya kini telah lumpuh. Dilumpuhkan oleh situasi dan kondisi akibat ketatnya pengawasan dalam sega-la bidang" (paragraf 5). Sementara bagi si lumpuh dan si buta, hal itu tidak ada pengaruhnya. Bagi si buta, walaupun diri-nya buta tapi tak ada yang menghalanginya untuk mengetahui keadaan orang lain atau berbuat baik pada orang lain (paragraf 6).

Allah itu telah menciptakan manusia dengan sesempurnanya. Allah telah menciptakan bentuk tubuh manusia dengan lebih baik. Allah memberikan kelebihan manusia dengan akalnya.

Adanya pengawasan yang ketat terhadap penggunaan uang negara agar tidak dikorupsi oleh para pejabat negara adalah tindakan baik dan benar. Bukankah dalam agama Islam sudah diperingatkan kepada umat-Nya untuk selalu mencari reski yang halal dan memberikan makan anak-istri dari reski yang halal tersebut. Supaya daging yang tumbuh dan darah yang mengalir dalam tubuh ini suci sehingga terhindar dari berbagai penyakit. Agama Islam melarang umatnya untuk berbuat korup karena perbuatan tersebut tidak diridhoi Allah.

Mereka yang merasa lumpuh atau dilumpuhkan karena adanya sebuah sistem pengawasan yang baik adalah orang-orang yang telah ditutup pintu hatinya akan kebenaran. Ditutupnya pintu hati manusia tersebut mungkin juga ada hubungan reski yang diterima dan makanan yang dimakan dari sesuatu yang tak jelas sumbernya (korup). Satu jalan untuk bisa keluar dari situasi ini adalah kembali ke jalan yang benar. Jalan yang diridhoi Allah.

\section{(2) Kejujuran}

Adapun yang dimaksud dengan nilai kejujuran di sini adalah sikap atau perbuatan untuk menyatakan sesuatu sesuai apa adanya, tidak ada yang ditutup-tutupi atau disembunyikan. Seiring perubahan zaman dan semakin rendahnya pemahaman dan pengaplikasian nilai-nilai agama dalam kehidupan sehari-hari, sangat sulit ditemukan orang jujur. Terkadang jadi orang jujur itu juga memiliki resiko berat, yaitu selalu tidak disenangi orang-orang yang tak mau jujur.

Tokoh Buta dan Lumpuh memiliki sikap jujur. Kejujuran tersebut sebagaimana terlihat dari ungkapan yang mereka ungkapkan atas prilaku yang tidak baik kepadanya.

"Yang Buta menganggap apa yang dilontarkan orang lain kepada dirinya hanyalah perkiraan-perkiraan mereka saja terhadap dunia yang mereka tidak pahami. Yang Buta meyakini bahwa dunia ini memang gelap tapi mungkin tidak segelap dunia mereka yang menertawakannya. Ba-gaimana gelapnya, hanya dirinya sendiri yang mengetahui. Mereka sok tau dengan duniaku", yang Buta membatin" (paragraf 9).

Apa yang diungkapkan tokoh Yang Buta terhadap anggapan orang kepada dirinya adalah sebuah kejujuran. Ungkapan bahwa orang buta itu tidak bisa melihat, tidak normal, dan sebagainya hanyalah ungkapan orang yang tak buta dengan ukuran dirinya sendiri. Namun tidaklah demikian bagi orang buta itu sendiri. Bagi mereka hanya mata mereka yang buta, tetapi, pikiran dan hatinya mereka tetap bisa melihat.

"Bagi si buta, walaupun dirinya buta tapi tak ada yang menghalanginya untuk mengetahui keadaan orang lain atau berbuat baik pada orang lain" (paragraf 6).

Benar adanya bahwa selama ini kita melihat orang buta itu sebagai sosok yang tidak bisa melihat apa-apa. Namun kita tak pernah berpikir, ternyata orang buta itu mampu pergi kemana ia suka. Dirinya tahu mana jalan yang boleh ditempuh dan mana yang dilarang. Sikap seperti ini tentunya tidak baik karena suka melecehkan orang lain. Bukankah di hadapan Allah nantinya, hanya yang membedakan kita sesame manusia ini adalah kuantitas dan kualitas amal ibadah 
yang kita miliki. Bukan kegagahan atau kecantikan.

\section{(3) Toleransi}

Adapun yang dimaksud nilai toleransi disini adalah sikap saling menghargai dan saling menerima akan perbedaan yang ada. Dalam cerpen Waskat karya Wisran Hadi ini terkandung nilai-nilai karakter yang tidak toleransi, yaitu tidak adanya saling menghargai sesame bangsa dan tidak adanya saling menerima perbedaan yang ada. Mereka yang sehat atau tidak cacat sering memberikan sapaan yang tidak baik kepada mereka yang cacat. Tokoh Yang Buta sering diberikan sapaan yang tidak baik, yaitu Si Buta. Begitu juga kepada orang lumpuh sering diberikan sapaan Si Lumpuh. Saan itu jelas bukan sapaan nama aslinya, melainkan sapaan atas kekurangan atau kecacatan yang dimiliki orang lain. Namun Si Buta dan Si Lumpuh menerima saja sapaan itu dengan sabar.

"Kau tidak akan mampu mengawasi apa-apa dalam kegelapan abadi, kata orang-orang yang mengganggu. Yang Buta tetap saja tersenyum dan mengangguk tersenyum" (paragraf 8)

Prilaku seperti ini tentunya tidaklah elok. Tidak elok melecehkan orang lain. Tidak elok menonjolkan kekurangan orang lain. Prilaku ini juga tentunya sangat bertentangan dengan ideologi Pancasila yang kita anut. Bukankah sejarah telah membuktikan bahwa kemerdekaan yang kita peroleh karena adanya sikap saling menghormati sesama sehingga terbentuk rasa persatuan antar kita. Oleh sebab itu, sikap in-toleransi tidaklah baik dan harus dibuang jauh-jauh dari bumi Indonesia.

\section{(4) Disiplin}

Adapun yang dimaksud disiplin di sini adalah sikap menjunjung tinggi norma atau peraturan yang ada dalam tata kehidupan yang ada. Tokoh buta dan lumpuh dalam cerpen ini walaupun mereka memiliki kekurangan tetapi mereka taat akan aturan yang ada. Mereka tidak pernah melakukan pelanggaran sehingga dirinya harus berurusan dengan penegak hukum. Dalam cerpen ini tidak ditemukan si lumpuh dan si buta ditangkap polisi karena telah melanggar hukum melakukan sesuatu.

\section{(5) Kerja Keras}

Adapun yang dimaksud kerja keras di sini adalah sikap untuk tidak menerima keadaan begitu saja. Adanya motivasi yang tinggi untuk selalu berusaha semampunya. Si Lumpuh dan Si Buta di sini tidak duduk saja di rumah untuk memperoleh reskinya. Si Lumpuh dan Si Buta bekerja sama untuk memperoleh reski demi kelangsungan hidupnya.

"Dengan menggabungkan diri keduanya, mereka dapat saling bantu" (paragraf 110).

Maksudnya, adanya kerja sama antara si lumpuh dan si buta merupakan sebuah kekuatan keduanya. Mereka dapat saling berbagai pengetahuan dan dapat menjalankan kehidupannya dengan baik.

Apa yang dilakukan si buta dan si lumpun ini adalah contoh bagi yang sempurna untuk tidak bermalas-masalan. Hidup ini adalah perjuangan. Oleh sebab itu untuk memperoleh reski yang banyak harus mau bekerja keras, pantang menyerah.

Si lumpuh dan si buta sebetulnya dapat saja dia mengemis di jalan atau di depan masjid untuk memperoleh reskinya. Namun hal itu ternyata tidak dilakukan oleh keduanya. Keduanya mau bekerja keras untuk kelangsungan hidupnya.

\section{(6) Mandiri}

Yang dimaksud dengan mandiri di sini adalah dapat melakukan sesuatu tanpa harus bergantung dengan orag lain. Si Buta dan si Lumpuh merupakan tokoh yang mandiri sebab tidak mau menggantungkan nasibnya kepada orang lain. Mereka bekerja sama untuk memperoleh reski demi menghidupkan dirinya masing-masing. Mereka tidak pasrah dengan kondisi kekurangan yang dia miliki. Mereka sangat 
yakin bahwa Allah telah menjamin akan reskinya sehingga dirinya selalu tenang dalam menghadapi persoalan hidupnya. Walaupun orang lain menganggapnya orang yang kurang dan perlu diperhatikan. Akan tetapi bagi diri mereka tidaklah demikian. Oleh sebab itu, mereka mengatakan bahwa dirinyalah yang tahu akan apa yang ada dalam dirinya.

\begin{abstract}
"Yang Buta menganggap apa yang dilontarkan orang lain kepada dirinya hanyalah perkiraan-perkiraan mereka saja terhadap dunia yang mereka tidak pahami. Yang Buta meyakini bahwa dunia ini memang gelap tapi mungkin tidak segelap dunia mereka yang menertawakannya. Ba-gaimana gelapnya, hanya dirinya sendiri yang mengetahui. Mereka sok tau dengan duniaku", yang Buta membatin" (paragraf 9).
\end{abstract}

\section{(7) Komunikatif}

Yang dimaksud komunikatif di sini adalah kemampuan menjalin hubungan dengan orang lain. Kemampuan bersosial dengan masyarakat sekitarnya. Si Lumpuh dan Si Buta memiliki kemampuan komunikasi dengan orang lain. Mereka mampu menyampaikan apa yang dirasakannya kepada orang lain dan mampu juga merasakan apa yang dirasakan orang lain. Hal ini sebagaimana terlihat komunikasi yang mereka lakukan dengan tokoh Yang Budiman.

"Yang lumpuh kan hanya kaki saya, pak Budiman. Ibarat mobil, bannya saja yang kemps. Yang lain kan masih baik. Jadi, saya hanya meminjam ban teman saya ini", jawab yang lumpuh sambil menepuk-nepuk kepala Yang Buta" (paragraf 15).

"Sebagaimana mobil tadi, lampu saya memang rusak. Tapi saya tetap tahu mana jalan yang harus ditempuh. Agar tidak ditangkap polisi karena kendaraan tidak punya lampu, kan tidak ada salahnya saya memakai lampu teman saya ini, jawab Yang Buta sambil menpuk kaki yang lumpuh" (paragraf 16).

"Jadi, soal rencana Bapak Yang Budiman untuk menjadikan kami tidak saling menunggangi sebaiknya dipertimbangkan lagi, kata yang Lumpuh ramah" (paragraf 17).

Berdasarkan dua dialog tersebut terlihat bahwa tokoh Yang Lumpuh dan tokoh Yang Buta memiliki kemampuan komunikasi yang baik. Kedua tokoh mampu menyampaikan perasaan dan pikirannya kepada orang lain, khususnya kepada tokoh bernama yang Budiman.

\section{(8) Cinta Damai}

Adapun yang dimaksud dengan cinta damai di sini adalah sikap untuk tidak melakukan segala sesuatu menjadi rusuh, ribut, huru-hara, atau bising. Suatu sikap untuk selalu hidup nyaman, aman, dan tentram. Walaupun begitu negatifnya pandangan yang ditujukan kepada si lumpuh dan si buta, akan tetapi Yang Buta dan Yang Lumpuh menerimanya saja dengan sabar. Mereka tidak mau membuat keributan. Bukannya mereka takut melainkan mereka memandang hal itu tidak ada gunanya. Oleh sebab itu, jalan terbaik hanya bisa dilakukan dengan cara memberikan anggukan, mengucapkan kata ya atau dengan tersenyum.

"Kau tidak akan mampu mengawasi apa-apa dalam kegelapan abadi, kata orang-orang yang mengganggu. Yang Buta tetap saja tersenyum dan mengangguk tersenyum" (paragraf 8).

Anggukan, ucapan ya, dan senyum adalah suatu sikap atau respon yang diberikan tokoh Yang Lumpuh dan tokoh Yang Buta, untuk menghindari terjadinya keributan, percecokan, atau perkelahian. Sikap untuk selalu menjaga situasi tetap aman dan damai. Walaupun mereka harus mengorbankan perasaannya. Bagi mereka, dengan kondisi tubuh yang kurang tersebut bukanlah kehendaknya sendiri melainkan semuanya sudah skenario Allah. Jadi, siapa yang menghina perbuatan Allah, maka hanya Allahlah yang memiliki hak untuk membalasnya. 


\section{(9) Peduli Sosial}

Yang dimaksud dengan peduli sosial di sini adalah sikap untuk selalu berbuat baik kepada orang lain. Sikap yang mau mengorbankan pikiran, tenaga, maupun materil demi kesejahteraan orang lain. Sikap ini dimiliki tokoh bernama Yang Budiman. Tokoh yang Budiman kasihan melihat si buta dan si lumpuh susah payah mencari nafkah untuk menghidupi diri mereka masing-masing. Tokoh Yang Budiman terdorong hatinya untuk membelikan tokoh Yang Lumpuh sebuah kursi roda agar mereka tidak susah berjalan. Begitu juga kepada tokoh Yang Buta. Yang Budiman berniat membantu biaya operasi matanya agar dapat melihat sehingga mampu berjalan sendiri dan mampu mencari nafkah dengan baik.

\begin{abstract}
"Yang Budiman kemudian mencoba mengatasi dan membantu kedua insane itu. Dia berencana membelikan sebuah kursi roda untuk Yang Lumpuh agar tidak terus menerus menunggangi orang buta. Dan mata Yang Buta diusahakan pula untuk dioperasi agar Yang Buta jangan semena-mena membawa orang lumpuh kemana-mana" (paragraf 14).
\end{abstract}

Apa yang dilakukan oleh tokoh bernama Yang Budiman tersebut merupakan sikap peduli sosial, sikap peduli kepada orang lain. Yang Budiman merasa kasihan kepada tokoh bernama Yang Lumpuh dan Yang Buta. Oleh sebab itulah timbul ide dalam pikirannya untuk membantu keduanya. Yang Budiman ingin membelikan kursi roda kepada yang lumpuh untuk dapat berusah sendiri. Begitu juga kepada tokoh Yang Buta. Yang Budiman berencana akan mengusahakan operasi mata kepadanya agar matanya dapat melihat lagi. Dengan demikian, Yang Buta dapat melakukan aktifitasnya secara maksimal.

\section{SIMPULAN}

Berdasarkan hasil analisis cerpen Waskat karya Wisran Hadi, maka dapat disimpulkan bahwa cerpen Waskat karya Wisran Hadi ini mengandung nilai-nilai pendidikan karakter, seperti nilai: (1) relegius, (2) kejujuran, (3) toleransi, (4) disiplin, (5) kerja keras, (6) mandiri, (7) komunikatif, (8) cinta damai, dan nilai (9) peduli sosial. Kesembilan nilai tersebut menyatu keberadaannya dalam cerpen. Dengan demikian, dapat disimpulkan bahwa Wisran Hadi telah mampu memanisfetasikan nilai-nilai pendidikan karakter dengan baik di dalam cerpennya sehingga cerpennya yang berjudul Waskat ini menjadi cerpen yang bermutu atau berkualitas. Cerpen ini dapat dijadikan bacaan berkualitas untuk semua umur. Selain itu, karena cerpen ini juga diselingi dengan humor-humor kecil maka cerpen ini juga dapat menjadi hiburan bagi pembacanya.

\section{DAFTAR RUJUKAN}

Asri,Y.(2013).“'Refleksi Ideologi Perem-puan dalam Novel Perempuan Karya Wisran Hadi”. Diakses dari bttp:// journal.ugm.ac.id/jurnal-bumaniora/ artikel/view/1814

Departemen Pendidikan Nasional.(1991). Buku Panduan Pelaksanaan Pendidikan Karakter. Diakses dari http://repository.unand.ac.id/22742/I/4/Panduan_Pen didikan_Karakter

Djamaris, E.(1994). Sastra Daerah di Sumatera: Analisis Tema, Amanat, dan Nilai Budaya. Jakarta: Balai Pustaka

Esren, M.(1999). Kajian Transformasi Budaya. Bandung: Angkasa

Faruk.(1994). Sosiologi Sastra. Yogyakarta: Pustaka Pelajar

Fokkema, DW., \& Alrud KunneIBSCH.(1998). Teori Sastra Abad Kedua Puluh. Jakarta: PT Gramedia

Ghony, M. D \& Almanshur, Fau-zan.(2012). Metodologi Penelitian Kualitatif. Yogyakarta: PT ARRUS-Media

Hadi, W.(1995). Cerpen 'Waskat'. Jakarta: Harian Umum Republika, 13 Agustus 1995.

Mahayana, M.S.(2007). Ekstrinsikalitas Sastra Indonesia. Jakarta: PT Rajagrafindo Persada

Miles, B.W.,\& Huberman, M.(1992). Analisis Data Kualitatif. Jakarta: UIP 
Nurgiyantoro, B.(1995). Teori Pengkajian Fiksi. Yogyakarta: Gadjah Mada University Press

Rais.(2017). “Absurditas dalam Naskah Drama 'Jalan Lurus' Karangan Wisran Hadi dan Implikasinya dalam Pembelajaran Sastra di SMA". Diakses dari: http://jounal.unj.ac.id/unj/index. php /aksis/article/view/325

Ratna, N.K.(2011). Teori, Metode, dan Teknik Penelitian Sastra. Yogyakarta: Pustaka Pelajar

Segers, R.T.(2000). Evaluasi Teks Sastra. Yogyakarta: Adicita Karya Nusa

Sumardjo, J., \& Saini, K.M.(1986). Apresiasi Kesusastraan. Jakarta: PT Gramedia

Syarbaini, S.(2014). Pendidikan Kewarganegaraan untuk Perguruan Tinggi Implementasi Nilai-Nilai Karakter Bangsa. Bogor: Ghalia Indonesia

Teeuw, A.(1991). Membaca dan Menilai Sastra. Jakarta: PT Gramedia 